\title{
REFORMA TRABALHISTA E O CONCEITO DE SISTEMA JURÍDICO
}

\author{
Camila Miranda de Moraes* \\ Fausto Siqueira Gaia**
}

SUMÁRIO: Introdução; 2 Conceito de sistema; 3 Características do sistema de Direito do Trabalbo brasileiro; 4 Análise de alguns pontos da reforma trabalbista (lei 13467 de 13/07/2017); 5 Considerações finais; Referências.

RESUMO: A gênese do trabalho humano remonta os esforços físicos, punições. A etimologia da palavra trabalho, que vem do latim "tripaliare" que significa torturar, reflete em sua evolução histórica e na evolução da disciplina jurídica que hoje conhecemos como direito do trabalho. No curso da história, o trabalho assumiu diversas feições - servidão, escravidão, corporações de ofício - o que gerou a necessidade do surgimento de uma disciplina jurídica autônoma que regulasse tais relações, que hoje denominamos direito do trabalho. $\mathrm{O}$ objetivo do presente artigo é estudar o conceito de sistema jurídico e suas características para investigar quais as características do sistema de direito do trabalho no Brasil e pesquisar se a denominada reforma trabalhista veiculada pela lei 13467 de 13/07/2017 guarda pertinência com o sistema do direito do trabalho brasileiro e em que medida.

PALAVRAS-CHAVE: Sistema; Direito do trabalho; Reforma trabalhista; Lei 10467/2017; Princípios.

\section{LABOUR REFORM AND THE CONCEPT OF JURIDICAL SYSTEM}

ABSTRACT: The birth of human labour tracks back to physical efforts and punishments. The etymology fo the word labour, that comes from the latin word "tripaliare", which means to torture, reflects in its historical evolution and in the evolution of the juridical discipline Labour Law as we now know it. In the course of history labour has assumed many facets - servitude, slavery, labour corporations - and that generated the need of na autonomous juridical discipline to regulate those facets, which nowadays we call Labour Law. This article aims to study the concept of juridical system and its carachteristics to investigate which of them form the Labour Law juridical system in Brazil and research if the so-called labour reform (L.13467/2017) adapts to the brazilian Labour Law juridical system and to what extent.

KEY WORDS: System; Labour Law; Labour reform; Law 10467/2017; Principles.

Doutoranda em Direito do Trabalho (PUC-SP) Mestre em Direito Constitucional (UNIFOR) Juíza do Trabalho Substituta (TRT 7a Região), Brasil. E-mail: camillebr@yahoo.com

** Doutorando em Direito do Trabalho (PUC-SP) Mestre em Direitos e Garantias Fundamentais (FDV) Juiz do Trabalho Substituto (TRT 17a Região), Brasil. 


\section{REFORMA LABORAL Y EL CONCEPTO DE SISTEMA JURIDICO}

RESUMEN: El nascimiento del trabajo humano remonta esfuerzos físicos, punición. La etmología de la palabra trabajo, que viene del latino "tripaliare" que significa torturar, reflije su evolucion histórica y la evolución de la disciplina jurídica que hoy llamamos derecho del trabajo. En la historia el trabajo ha tenido inúmeros aspectos - servidumbre, esclavitud, corporación de ofícios - que han generado la necesidad de uma disciplina jurídica autonoma para regular tal relación, que hoy llamamos derecho laboral. El objetivo es estudiar el concepto de sistema jurídico, sus características, investigar las características del sistema de derecho laboral en Brasil y pesquisar se la reforma laboral de la ley 13467/2017 es congruente com el sistema de derecho laboral brasileño.

PALABRAS CLAVE: Sistema; Derecho laboral; Reforma laboral; Ley 10467/2017; Princípios.

\section{INTRODUÇÃO}

A gênese do trabalho humano remonta os esforços físicos, punições. A palavra trabalho significa "ocupar-se em algum mister; exercer seu ofício. Do latim 'tripaliare', torturar, derivado de 'tripalium', instrumento de tortura composto de três paus; da ideia inicial de sofrer; passou-se à de esforçar-se, lutar, pugnar e, por fim, trabalhar"03.

A etimologia da palavra trabalho reflete em sua evolução histórica e na evolução da disciplina jurídica que hoje conhecemos como Direito do Trabalho. No curso da história, o trabalho assumiu diversas feições - servidão, escravidão, corporações de ofício - o que gerou a necessidade do surgimento de uma disciplina jurídica autônoma que regulasse tais relações, que hoje denominamos direito do trabalho.

O objetivo do presente artigo é estudar o conceito de sistema jurídico e suas características para investigar quais as particularidades do sistema de direito do trabalho no Brasil e pesquisar se a denominada reforma trabalhista veiculada pela lei 13467 de 13/07/2017 guarda pertinência com o sistema do direito do trabalho brasileiro e em que medida o faz. Procura-se abordar o tema a partir de um viés científico, que busca afastar-se da linha de debates apaixonados e que fogem da

${ }^{03}$ CUNHA, Antônio Geraldo da. Dicionário Etimológico Nova Fronteira da Língua Portuguesa. 2. ed., Rio de Janeiro, Nova Fronteira, 1986, p.779. 
necessária análise científica imparcial que se precisa ter.

$\mathrm{O}$ ordenamento jurídico brasileiro possui um vasto arcabouço de normas jurídicas protetoras dos direitos sociais laborais no âmbito constitucional e infraconstitucional.

No plano constitucional há de se observar que os valores sociais do trabalho, da livre iniciativa e dignidade da pessoa humana estão inscritos como fundamentos da República Federativa do Brasil (art.1 ${ }^{\circ}$, Constituição Federal de 1988); o trabalho, ademais, está inserido em meio a outros direitos sociais previstos no $\operatorname{art}^{\circ} 6^{\circ} \mathrm{da}$ Constituição Federal.

Por sua vez, o artigo $7^{\circ}$ da Constituição Federal, nos seus 34 incisos, traz uma lista meramente exemplificativa dos direitos dos trabalhadores urbanos e rurais, o que significa dizer que há permissão para criação ou adoção de outros desde que visem à melhoria da condição social dos trabalhadores - conclusão extraída da parte final do caput do mesmo dispositivo constitucional.

A pesquisa seguiu quanto aos aspectos metodológicos o método dedutivo. As hipóteses apresentadas foram investigadas mediante pesquisa bibliográfica, em que são analisadas algumas obras que tratam do assunto, e pesquisa documental, pois exploramos diversos diplomas normativos existentes atinentes aos tópicos discutidos. A tipologia da pesquisa, segundo a utilização dos resultados, é pura. Segundo a abordagem, a tipologia da pesquisa é qualitativa, visto que busca desenvolver a problemática com base numa pesquisa subjetiva, ou seja, preocupando-se com o aprofundamento e abrangência da compreensão das ações e relações humanas. Quanto aos objetivos, a pesquisa é descritiva e exploratória, uma vez que procura aperfeiçoar as sugestões e ajudará na formulação de hipóteses para pesquisas posteriores.

\section{CONCEITO DE SISTEMA JURÍDICO}

Um dos primeiros estudiosos a perscrutar de maneira crítica sobre a ideia de sistema na ciência do direito foi Karl Engisch em 1935. ${ }^{04}$ Depois dele muitos vieram, a exemplo, dentre outros, de Tércio Sampaio Ferraz Júnior, Lourival Vilanova, ClausWilhelm Canaris, Karl Larenz, Rudolf Stammler, Giorgio del Vecchio, Friedrich K. Savigny, Gustav Radbruch.

Ao conceituar o que seria ciência, Maria Helena Diniz afirma que ciência é um complexo de conhecimentos ordenados e conexos entre si, cujo objetivo é dar

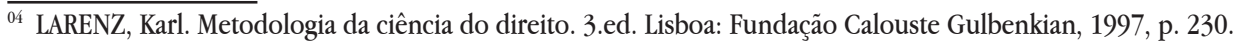


às suas constatações um caráter descritivo, genérico, comprovado e sistematizado. Ciência é um saber metodicamente fundado, demonstrado e sistematizado. ${ }^{05}$

Segundo a autora a ideia de sistema é de fundamental importância por ser o principal argumento para afirmar a cientificidade de algo. A justificação do saber científico decorre da sistematização.

Explica ela que a palavra sistema é de origem grega e significa "aquilo que é construído" (syn-istemi). Nas palavras de Maria Helena Diniz o sistema

é um todo organizado racionalmente e planejado metodicamente, portanto significa nexo, uma reunião de elementos, e método, um instrumento de análise. A sistematização é uma operação lógica que estabelece um nexo entre os elementos do direito, que constituem o objeto da análise do jurista, para dar uma unidade. De modo que o sistema não é uma realidade, é o aparelho teórico, mediante o qual se pode estudá-la. É, por outras palavras, o modo de ver ou de ordenar, logicamente, a realidade, que não é sistemática. Todo o sistema é uma reunião de objetos de seu estudo e seus atributos ou elementos (repertório) relacionados entre si, conforme certas regras (estrutura) que variam de concepção para concepção. ${ }^{06}$

Em obra específica sobre o tema, Canaris ressalta que ainda na atualidade mantém sua importância à definição ou conceito clássico de sistema formulado por Kant, segundo o qual o sistema é "um conjunto de conhecimentos ordenado segundo princípios" ${ }^{07}$

Consoante leciona Canaris, o sistema é definido como uma "ordem axiológica ou teleológica de princípios jurídicos gerais" ${ }^{\text {. }}$. Ao tratar de quais seriam os marcos distintivos de um sistema, o mesmo autor aponta a ordem e a unidade e explica que para que exista um sistema deverá haver certa "ordem de valores, de conceitos teleológicos ou de institutos jurídicos"09. O sistema jurídico seria um sistema aberto já que o conhecimento científico não é pleno, mas incompleto, além do fato de que os valores que inspiram as normas do ordenamento jurídico são mutáveis com o passar do tempo.

José Roberto Vieira indica três noções possíveis de sistema, apontando a terceira como aquela apta a refletir o significado de sistema na ciência do direito: a)

\footnotetext{
${ }^{05}$ DINIZ, Maria Helena. Sistematização: problema central da ciência jurídica. Revista de Direito Brasileira, São Paulo, v. 13, n. 6, p. 88-94, jan./abr. 2016.

${ }^{06}$ DINIZ, Maria Helena. Sistematização: problema central da ciência jurídica. Revista de Direito Brasileira, São Paulo, v. 13, n. 6, p. 88-94, jan./abr. 2016.

${ }^{07}$ CANARIS, Claus-Wilhelm. Pensamento sistemático e conceito de sistema na ciência do direito. 5.ed. Lisboa: Fundação Calouste Gulbenkian, 2012, p.10.

${ }^{08}$ Idem, p.280.

${ }^{09}$ Ibidem, p.280.
} 
repertório e estrutura; b) repertório, estrutura e unidade; c) repertório, estrutura, unidade e coerência. ${ }^{10}$

Essa noção de ordem para facilitar o conhecimento, para nutrir a coerência e a lógica é característica distintiva do que deve ser um sistema jurídico. No dizer de Karl Larenz, "onde quer que tenhamos de tratar como uma verdadeira ordem jurídica e com a sua imposição espiritual, aí será imprescindível a ideia de sistema."11

Ainda sobre o conceito de sistema, sustenta Tacio Lacerda Gama que a expressão significa

existência de um conjunto formado por elementos que se relacionam segundo certos padrões de racionalidade. Nesse sentido, Lourival Vilanova afirmava que "onde há sistema há relações e elementos, que se articulam segundo leis". Por isso, falar em "sistema" é falar na totalidade de elementos, reunidos por uma característica comum e organizados de acordo com certos padrões. ${ }^{12}$

Portanto, o sistema é uma construção epistemológica realizada pelo jurista com o propósito de conhecer e organizar o ordenamento jurídico para facilitar a aplicação do direito e a consequente solução dos problemas que surgem na vida cotidiana. Para que haja ciência não basta haver sistematização. Além da organização das partes de um todo no sistema, é imprescindível que haja coerência lógica e unidade de sentido. São características de um sistema jurídico o nexo entre seus elementos, a coerência entre eles, serem reunidos e organizados de forma lógica e relacionados entre si.

Nesse sentido importante a síntese feita por Paulo Issamu Nagao:

Em qualquer campo do conhecimento humano em que houver a congregação de diversos elementos (feição concreta) e aspectos conceituais (face abstrata) que se coordenam entre si e se organizam estruturalmente para a consecução de determinado(s) escopo(s) estará presente a noção de sistema, de modo que se pode falar, v.g., de sistema jurídico, judicial, constitucional, ou processual, sobressaindo-se a ideia de unidade, organização e finalidade. ${ }^{13}$

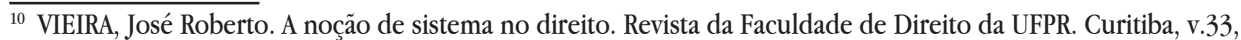
p.53-64, 2000. Disponível em: < http://revistas.ufpr.br/direito/article/download/1844/1540> Acesso em 20 nov. 2017.

${ }^{11}$ LARENZ, Karl. Metodologia da ciência do direito. 3.ed. Lisboa: Fundação Calouste Gulbenkian, 1997, p.231.

${ }^{12}$ GAMA, Tacio Lacerda. Sistema jurídico - Perspectiva dialógica. Enciclopédia jurídica da PUC-SP. Celso Fernandes Campilongo, Alvaro de Azevedo Gonzaga e André Luiz Freire (Coord.). Tomo: Teoria Geral e Filosofia do Direito. São Paulo: Pontifícia Universidade Católica de São Paulo, 2017. Disponível em: < https://enciclopediajuridica.pucsp.br/verbete/100/edicao-1/sistema-juridico---perspectiva-dialogica $>$ Acesso em 03 maio. 2017.

${ }^{13}$ NAGAO, Paulo Issamu. O papel do juiz na efetividade do processo civil contemporâneo. São Paulo: Malheiros, 2016, p.172. 
O sistema, portanto, é um método de análise, a forma metodológica de estudar o direito colocando em ordem o que está em desordem. Conhecer o sistema de direito do trabalho brasileiro implica estudar suas características, sua estrutura e diretrizes para diferenciá-lo de outros sistemas.

\section{CARACTERÍSTICAS DO SISTEMA DE DIREITO DO TRABALHO BRASILEIRO}

Com a finalidade de analisar as características do sistema de direito do trabalho nacional faremos uma digressão histórica para verificar a evolução e características dos direitos trabalhistas nas Constituições brasileiras.

No Brasil, o período de maior significância para o direito do trabalho foi uma parte da denominada Era Vargas, que compreende o período de 1930 até 1945. Não podemos, entretanto, deixar de analisar as mudanças ocorridas no período que vai desde a Constituição do Império, em 1824, até a Constituição de 1988.

O estudo das cartas constitucionais brasileiras demonstra de maneira clara a evolução do pensamento constitucional brasileiro e do próprio direito do trabalho nacional.

A Constituição de 1824, outorgada por dom Pedro I, não tratou dos direitos sociais dos trabalhadores. Esta Carta tinha inspiração na filosofia liberal da revolução francesa, e limitou-se a proibir, no seu artigo 179, XXV'14, a existência das corporações de ofício, como fora feito na França em 1791, por meio da lei Le Chapelier. A inovação da Carta de 1824 foi a existência do poder moderador, do qual o imperador era titular.

Houve a abolição da escravatura em 1888 e, no ano seguinte, a proclamação da República. Em 1891 foi promulgada a primeira Constituição da era republicana. Este diploma sofreu influências da Constituição norte-americana e, a exemplo da Constituição do Império, também não tratou dos direitos dos trabalhadores. "Fundamentalmente, a Constituição de 1891 adaptou ao Brasil o sistema constitucional de modelo norte-americano, à semelhança do que já tinham feito o México e a Argentina." 15

Comparando as Constituições de 1824 e 1891, Anderson Orestes Cavalcante Lobato afirma que

${ }^{14}$ NOGUEIRA, Octaciano. Constituições Brasileiras:1824.Brasília: Senado Federal e Ministério da Ciência e Tecnologia, Centro de Estudos Estratégicos, 1999, p.105.

${ }^{15}$ MIRANDA, Jorge. Manual de Direito Constitucional. 6. ed. Coimbra: Coimbra Editora, 1997, t. I, p.225. 
[...] a Monarquia constitucional brasileira, apesar de inserir no seu Texto constitucional os Direitos fundamentais individuais de cidadania, ignorava a sua dimensão coletiva, notadamente quanto ao exercício dos direitos políticos, porquanto admitia o voto censitário, bem como o direito de propriedade individual sobre pessoas, os escravos, que por uma ficção jurídica, considerava-se coisa. (sic) Desse modo, o avanço obtido com a primeira Constituição republicana foi deveras significativo. O final da monarquia representou para os brasileiros a conquistas, dos direitos coletivos e políticos, como o sufrágio universal.(sic) $)^{16}$

Limitou-se a Carta de 1891 a garantir "o livre exercício de qualquer profissão moral, intelectual e industrial" (art.72,\$24) e que "a todos é lícito associarem-se e reunirem-se livremente e sem armas" (art. $\left.72, \S^{\circ}\right){ }^{17}$

O pensamento da época entendia que a liberdade contratual era absoluta. Por tal razão a intervenção estatal nas relações entre os particulares, mormente nas relações trabalhistas, não era aceita. Entendia-se que o Estado não podia intervir na formação dos contratos, pois estaria restringindo a liberdade dos contratantes e ferindo-a, limitando o livre exercício de todas as profissões. Era a preponderância da doutrina do liberalismo, que não foi propícia para a evolução jurídica na ordem trabalhista.

Nessa época a população das cidades crescia, a imigração ocorria em grande escala, a industrialização no Brasil iniciava-se. Segundo Amauri Mascaro Nascimento,

Formavam-se, assim, as condições para que o trabalho subordinado viesse a ser regido por leis de proteção, mas, não obstante, o Poder Público, fiel ao princípio liberalista que o inspirava, mantinha-se alheio a qualquer reivindicação. Estas existiram. Atestam-no dois fatos: o elevado número de greves e o movimento político. ${ }^{18}$

Nesse período surgiram iniciativas isoladas buscando tratamento jurídico para as relações de trabalho. Por meio do decreto 1637/1907 foi assegurado o direito de sindicalização aos trabalhadores.

Com o Código Civil, em 1916, foi regulada a locação de serviços, antecedente histórico do contrato de trabalho.

\footnotetext{
${ }^{16}$ LOBATO, Anderson Orestes Cavalcante. Os direitos humanos na Constituição brasileira: os desafios da efetividade. In: MALUSCHKE, Gunther e outros (Org.) Direitos humanos e violência : desafios da ciência e da prática. Fortaleza: Fundação Konrad Adenauer, 2004, p.23.

${ }^{17}$ BALEEIRO, Aliomar. Constituições Brasileiras:1891. Brasília: Senado Federal e Ministério da Ciência e Tecnologia, Centro de Estudos Estratégicos, 1999, p.113.

${ }^{18}$ NASCIMENTO, Amauri Mascaro. Curso de Direito do Trabalho. 19. ed. São Paulo: Saraiva, 2004, p.62.
} 
Em 1919 a União legislou sobre seguro de acidentes do trabalho (lei 3724/1919), e em 1923 instituiu as Caixas de Aposentadorias e Pensão dos Ferroviários, com estabilidade decenal para os empregados das respectivas empresas (lei Eloi Chaves ${ }^{\circ}$ 4682/1923). O Conselho Nacional do Trabalho, vinculado ao Ministério da Agricultura, Indústria e Comércio, foi criado pelo decreto 16027/1923. Em 1924 surgiu o decreto 17934-A, o Código de Menores, que, entre outras coisas, dispôs sobre trabalho de menores.

Aliomar Baleeiro declara que tais fatos "foram os pródromos da legislação social que, logo após a Revolução de 1930, Lindolfo Collor induziria Vargas a aceitar." 19

Já em 1925, a lei 4982 concedia o direito a 15 dias de férias anuais remuneradas aos empregados de estabelecimentos comerciais, industriais, bancários e de caridade ou beneficentes.

Notamos, portanto, que a legislação existente era esparsa e específica, contemplando apenas determinados setores da sociedade com vantagens que poderiam ser encaradas como verdadeiros privilégios, e não direitos. Afinal, criavase uma verdadeira discriminação ao conceder certas vantagens somente a uma categoria específica de trabalhadores.

"Depois da Revolução de 3 de outubro de 1930 todas as Constituições dispuseram sobre os direitos sociais do trabalhador" é a constatação assinalada por Arnaldo Süssekind. ${ }^{20}$ Foi nesta época que houve o desenvolvimento da indústria no Brasil.

Em 26 de novembro de 1930, Getúlio Vargas, então chefe do Governo Provisório, criou o Ministério do Trabalho, Indústria e Comércio. A revolução paulista de 1932 incitou a necessidade de se promulgar uma nova Carta Constitucional, o que ocorreu em 1934. A inspiração para elaboração dessa Carta foi obtida na Constituição de Weimar (Alemanha, 1919) e na Constituição Republicana espanhola, de $1931 .^{21}$

Registra Ronaldo Poletti que o anteprojeto da Constituição de 1934 era inovador, pois trazia em seu texto inúmeros temas que não eram comumente abordados pelo direito constitucional, como religião, família, cultura e ensino, ordem econômica e social. Afirma o autor que "[...] deve decorrer daí a tendência

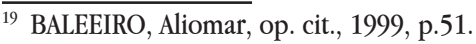

${ }^{20}$ SÜSSEKIND, Arnaldo. Direito Constitucional do Trabalho. 3. ed. Rio de Janeiro: Renovar, 2003, p.33.

${ }^{21}$ POLETTI, Ronaldo. Constituições Brasileiras: 1934. Brasília: Senado Federal Ministério da Ciência e Tecnologia, 1999, p.19. 
nacional de inserir na Carta Política dispositivos materialmente não-compreendidos pelo Direito Constitucional. Por isso, o texto projetado era mais extenso que o normal (135 artigos mais as disposições transitórias), embora não chegasse a ser uma enciclopédia."22

A nova Constituição mantinha o Brasil como uma República Federativa, havia separação dos poderes executivo, legislativo e judiciário, independentes entre si, e eleição direta dos membros dos poderes executivo e legislativo.

A Constituição de 1934 consagrou a justiça eleitoral (criada em 1932); reforçou os poderes do Congresso (em especial, da Câmara dos Deputados, eleita pelo povo e pelas organizações profissionais); previu formas de intervenção do Estado na economia e direitos sociais na linha da Constituição mexicana de 1917 e da Constituição de Weimar; introduziu o mandado de segurança, para garantia de certos direitos certos e incontestáveis contra actos inconstitucionais ou ilegais. ${ }^{23}$

No dia seguinte à promulgação da nova Carta, Getúlio Vargas foi eleito indiretamente presidente do Brasil, para um mandato de quatro anos.

Promulgada a 16 de julho de 1934, o novo Estado Político tornouse um marco na história do Direito Constitucional brasileiro pelas normas que inseriu no capítulo, até então inédito, sobre a ordem econômica e social. [...] A Constituição de 1934 procurou conciliar filosofias antagônicas emanadas das cartas magnas de Weimar (socialdemocrata) e dos Estados Unidos da América (liberal-individualista), além de mesclara a representação política resultante de voto direto com a escolhida pelas associações sindicais (representação corporativa). Foi-lhes, por isso, vaticinada vida efêmera, o que aconteceu. ${ }^{24}$

Foi a Carta de 1934 que previu a instituição da Justiça do Trabalho, que só foi criada em 1941 (já na vigência da Constituição de 1937, que trazia a mesma previsão), o sistema da pluralidade sindical, o repouso semanal preferentemente aos domingos (art.121, "e") e o salário mínimo "capaz de satisfazer, conforme as condições de cada região, às necessidades normais do trabalhador" (art.121 - b).

O capítulo II da Carta de 1934 era intitulado "Dos direitos e garantias individuais." O artigo 113 tratava de tais direitos. O art.113, 12 assegurava a liberdade de associação para fins lícitos. $\mathrm{O}$ inciso 13 do mesmo artigo garantia $\mathrm{o}$

\footnotetext{
${ }^{22}$ Idem, p.34.

${ }^{23}$ MIRANDA, Jorge, op. cit., 1997, t. I, p.228.

${ }^{24}$ SÜSSEKIND, Arnaldo, op. cit., 2003, p.34.
} 
livre exercício de qualquer profissão. Dentro do capítulo II estava o título IV "Da ordem econômica e social". Neste título havia previsão de reconhecimento dos sindicatos e associações profissionais (art.120), garantia da pluralidade sindical e completa autonomia dos sindicatos (parágrafo único do art.120). O artigo 121 da Constituição de 1934 elencava uma série de direitos trabalhistas como salário mínimo, proibição de diferença de salário para um mesmo trabalho em virtude de idade, sexo, nacionalidade ou estado civil, limitação da jornada diária de trabalho em 08 horas etc.

Sublinha Irany Ferrari a grande importância para a época do parágrafo $2^{\circ}$ do artigo 121 da Constituição Brasileira de 1934 porque ainda não existia a Consolidação das Leis do Trabalho, apenas poucas leis esparsas sobre o trabalho, e a Lei Maior tratou da proibição de discriminação entre o trabalho manual, intelectual ou técnico. ${ }^{25}$

Bem se vê que o curto tempo de vigência da Carta de 1934 não apaga sua importância histórica. As diretrizes nela lançadas foram reproduzidas na maioria das constituições posteriores. Percebemos que o grande salto para o direito do trabalho foi dado por ocasião da Constituição de 1934, haja vista a inserção de um título tratando da ordem econômica e social e trazendo diversas garantias aos trabalhadores.

Em 10 de novembro de 1937, foi promulgada no Brasil uma nova Carta Constitucional, inspirada na Constituição polonesa de 23 de abril de 1935. Esse período de nossa história é conhecido como "Estado Novo" (1937/1945). Foi nessa época que houve a promulgação da Consolidação das Leis do Trabalho - CLT, mais exatamente em $1^{\circ}$ de maio de 1943.

O "Estado Novo" era nitidamente intervencionista, principalmente na ordem econômica e social. A greve foi proibida por ser nociva à produção. Fixouse o princípio do sindicato único que somente seria legítimo se reconhecido pelo próprio Estado. ${ }^{26}$

O artigo 122 da Carta de 1937 trata dos direitos e garantias fundamentais, semelhantemente à Carta de 1934. Nos artigos 135 a 155 está o tratamento da ordem econômica e social. O artigo 137 traz 14 incisos contendo direitos dos trabalhadores. Dentre eles citamos o direito às férias ( "e) depois de um ano de serviço ininterrupto em uma empresa de trabalho contínuo, o operário terá direito a uma licença

${ }^{25}$ FERRARI, Irany et. al. História do trabalho, do direito do trabalho e da justiça do trabalho. São Paulo: $\operatorname{LTr}$, 1998 , p.56.

${ }^{26}$ Idem, p. 57. 
anual remunerada;"27), à indenização pela cessação da relação de emprego ("f) nas empresas de trabalho contínuo, a cessação das relações de trabalho, a que o trabalhador não haja dado motivo, e quando a lei não lhe garante a estabilidade no emprego cria-lhe o direito a uma indenização proporcional aos anos de serviço;"28), a impessoalidade da relação de emprego em relação ao empregador, garantindo a continuidade do emprego nos casos de sucessão do empregador ("g) nas empresas de trabalho contínuo, a mudança de proprietário não rescinde o contrato de trabalho, conservando os empregados, para com o novo empregador, os direitos que tinham em relação ao antigo;").

Em $1^{\circ}$ de maio de 1939 , com o decreto-lei 1237 , foi constituída a Justiça do Trabalho, que se instalou oficialmente em 01/04/1941, ainda no âmbito do Ministério do Trabalho e não do Poder Judiciário.

Foi na Constituição de 1946 que os órgãos da Justiça do Trabalho estavam divididos de maneira similar à de hoje em dia. Naquela época havia as Juntas de Conciliação e Julgamento (hoje Varas do Trabalho), os Tribunais Regionais do Trabalho e o Tribunal Superior do Trabalho.

A Carta de 1946 trouxe uma nova fase ao constitucionalismo brasileiro, uma vez que se tratava de uma carta de cunho socialdemocrata. Assim, percebemos o contraste entre a Constituição anterior, extremamente autoritária, e a Carta de 1946, que continuou a evolução das normas trabalhistas e do próprio direito do trabalho.

Aliomar Baleeiro e Barbosa Lima Sobrinho registram que a Assembleia Constituinte, formada para elaborar a Carta de 1946, contava com a participação de bancadas comunistas e trabalhistas, o que foi importante para determinar algumas mudanças no texto constitucional. ${ }^{29}$

O título IV da Constituição de 1946 tratava "Da declaração de direitos", e o capítulo II tratava "Dos direitos e das garantias individuais". O título V, "Da ordem econômica e social", trazia preceitos trabalhistas (artigo 145 a 162). A leitura do artigo 145 da Carta de 1946, o primeiro do título sobre a ordem econômica e social, já deixa antever o teor mais democrático e social da nova Constituição.

Art. 145 A ordem econômica deve ser organizada conforme os princípios da justiça social, conciliando a liberdade de iniciativa com a

\footnotetext{
${ }^{27}$ PORTO, Walter Costa. Constituições Brasileiras: 1937. Brasília: Senado Federal e Ministério da Ciência e Tecnologia, Centro de Estudos Estratégicos, 1999, p.105.

${ }^{28}$ Idem, p.105.

${ }^{29}$ BALEEIRO, Aliomar; LIMA SOBRINHO, Barbosa. Constituições Brasileiras: 1946. Brasília: Senado Federal e Ministério da Ciência e Tecnologia, Centro de Estudos Estratégicos, 1999, p.15.
} 
valorização do trabalho humano.

Parágrafo único. A todos é assegurado trabalho que possibilite existência digna. O trabalho é obrigação social. ${ }^{30}$

O artigo 157 era todo devotado à legislação do trabalho e estatuía, dentre outros preceitos, salário mínimo (inciso I), remuneração do trabalho noturno superior à do trabalho diurno (inciso III), "participação obrigatória e direta do trabalhador nos lucros da empresa, nos termos e na forma que a lei determinar" (inciso IV), assistência aos desempregados (inciso XV). A liberdade de associação foi garantida (artigo 159), as convenções coletivas reconhecidas (inciso XIII) e o exercício do direito de greve, outrora proibido em 1934, foi assegurado (artigo 158).

Em 1967 veio outra Carta Constitucional, que praticamente manteve os ditames da Constituição de 1946, e que sofreu ampla revisão pela Emenda Constitucional $\mathrm{n}^{\circ}$ 01, de 1969. Segundo Arnaldo Süssekind, "essa revisão não alterou o elenco dos direitos sociais trabalhistas, mas introduziu modificação de relevo quanto à finalidade da ordem econômica." ${ }^{31} \mathrm{O}$ voto nas eleições sindicais torna-se obrigatório e é criado o denominado imposto sindical. O salário-família e o fundo de garantia por tempo de serviço (FGTS) são instituídos.

Finalmente, em 05 de outubro de 1988, é promulgada a Carta Constitucional até hoje vigente, que trouxe inúmeros avanços tanto em termos do estudo da teoria da democracia quanto relativamente aos direitos trabalhistas. Para Daniel Sarmento, "do ponto de vista histórico a Constituição de 1988 representa o coroamento do processo de transição do regime autoritário em direção à democracia."”2

Nas palavras de Lenio Luiz Streck, a Constituição brasileira de 1988 é uma Constituição social, dirigente e compromissária, "alinhando-se com as Constituições europeias do pós-guerra." 33

Assim, a Carta Constitucional vigente contemplou, no seu artigo $7^{\circ}$, uma série de direitos de natureza trabalhista, como: seguro-desemprego; fundo de garantia por tempo de serviço (FGTS - que atualmente é regulado pela lei $\mathrm{n}^{\circ}$ 8036/1990); salário mínimo fixado em lei; piso salarial proporcional à extensão e à complexidade do trabalho (regulado pela lei complementar $\left.n^{\circ} 103 / 2000\right) ; 13^{\circ}$

\footnotetext{
${ }^{30}$ Idem, p.103.

31 SÜSSEKIND, Arnaldo, op.cit., 2003, p.36.

32 SARMENTO, Daniel. Por um constitucionalismo inclusivo: história constitucional brasileira, teoria da Constituição e direitos fundamentais. Rio de Janeiro: Lumen Juris, 2010, p.102.

33 STRECK, Lenio Luiz. Jurisdição constitucional e hermenêutica: uma nova crítica do direito. 2.ed. Rio de Janeiro: Forense, 2004, p.15.
} 
salário; remuneração do trabalho noturno superior à do diurno; irredutibilidade do salário salvo o disposto em acordo ou convenção coletiva; repouso semanal remunerado preferencialmente aos domingos; férias acrescidas de um terço; aviso prévio de no mínimo 30 dias; proibição de trabalho noturno, perigoso ou insalubre a menores de 18 anos, e de qualquer trabalho a menores de 16 anos, salvo na condição de aprendiz, a partir dos 14 anos; igualdade de direitos entre o trabalhador avulso e aquele que possui vínculo de emprego; extensão aos empregados domésticos do direito a salário mínimo, irredutibilidade do salário salvo o disposto em acordo ou convenção coletiva, $13^{\circ}$ salário com base na remuneração integral ou no valor da aposentadoria, repouso semanal remunerado preferencialmente aos domingos, gozo de férias anuais remuneradas com, pelo menos, um terço a mais do que o salário normal, licença à gestante, licença paternidade, aviso prévio de, no mínimo, 30 dias e aposentadoria.

Alguns desses direitos já eram regulados por legislação ordinária anterior a 1988, que se manteve sem alterações, por ter sido recepcionada pelo sistema constitucional vigente. Este é o caso da gratificação natalina, popularmente conhecida como $13^{\circ}$ salário, que foi criada pela lei 4090/1962, e do repouso semanal remunerado, regulado pela lei 605/1949, ambos integralmente recepcionados pela Constituição de 1988. Outros direitos constituíram novidade à época, como a licença paternidade de cinco dias regulada pelo art. $10, \S 1^{\circ}$ do Ato das Disposições Constitucionais Transitórias, e a licença à gestante de 120 dias, garantidos o emprego e o salário.

Arion Sayão Romita, diferentemente de grande parte dos doutrinadores, critica alguns aspectos da Constituição de 1988, dizendo que esta "sem dúvida introduz inovações, no intuito de implantar a democracia na regulação das relações de trabalho, mas conserva o essencial do regime antidemocrático, que deveria ter afastado por completo." ${ }^{34}$

Assiste alguma razão a Arion Sayão Romita, pois embora tenha introduzido, no que diz respeito aos direitos trabalhistas, muitas inovações, a Constituição de 1988 ainda manteve alguns dispositivos que remontam períodos autoritários de nossa história. Desta feita, a manutenção da unicidade sindical e da contribuição sindical compulsória, por exemplo, tem um caráter antidemocrático.

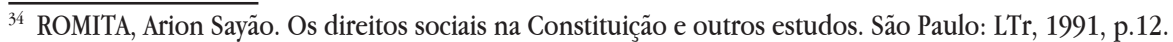


Embora criticada por alguns doutrinadores, como Arion Sayão Romita ${ }^{35}$, entendemos que a Constituição de 1988 foi inovadora. Com base no estudo do pensamento constitucional brasileiro, percebemos que a Constituição de 1988 buscou regular e garantir inúmeros direitos à classe trabalhadora, diferentemente das Constituições que a precederam. "Diversamente de todas as anteriores Constituições, a de 1988 ocupa-se dos direitos fundamentais com prioridade em relação às demais matérias." ${ }^{36}$

Como se esperava depois de tantas cartas constitucionais retrógradas e autoritárias, o espírito da Carta de 1988 é democrático. Entretanto, por excesso de zelo, o constituinte foi, por vezes, redundante ao tratar dos direitos trabalhistas, procurando evitar quaisquer dúvidas quando da exegese do texto constitucional. Tal desiderato, entretanto, não foi alcançado integralmente.

Exemplo dessa redundância pode ser visto no inciso XXVI do art. $7^{\circ}$ da Constituição, que trata do "reconhecimento das convenções e acordos coletivos de trabalho". Ora, se o inciso VI do art. $7^{\circ}$ já garante "irredutibilidade do salário, salvo o disposto em convenção ou acordo coletivo", que necessidade havia de inserir no inciso XXVI o reconhecimento dos instrumentos coletivos?

Houve grande preocupação do legislador constituinte em instituir ou garantir a inserção no texto da Carta Magna de diversos tipos de direitos. No que pertine aos direitos sociais, percebe-se que sua inclusão no texto constitucional foi uma espécie de promessa do legislador que, no entanto, deixou de lado as questóes relativas à efetividade de tais normas.

Tal problema ou constatação também encontra explicação na história. Anderson Orestes Cavalcante Lobato afirma que

[...] é preciso entender que a participação popular na constituinte ofereceu à Constituição de 1988 uma legitimidade sem precedentes na história constitucional brasileira. As expectativas criadas pela Nova República foram de uma grande transformação social que pudesse encerrar não somente com o ciclo autoritário, marcado pela institucionalização da violência; mas, igualmente, eliminar a imensa desigualdade social e econômica que provoca a banalização da violência nas relações quotidianas. ${ }^{37}$

\footnotetext{
35 "Antecipando a conclusão, digo que minha impressão a respeito da regulação dos direitos dos trabalhadores pela Constituição de 5 de outubro de 1988 não é lisonjeira. Não vou tecer loas ao novo texto constitucional, contrariando a tendência já revelada por alguns estudiosos, que destacam o "caráter progressista" da Carta Magna recentemente promulgada." ROMITA, Arion Sayão, op.cit., 1991, p. 11.

${ }^{36}$ MIRANDA, Jorge, op.cit., 1997, t. I, p.231.

${ }^{37}$ LOBATO, Anderson Orestes Cavalcante. Os direitos humanos na Constituição brasileira: os desafios da efetividade. In: MALUSCHKE, Gunther e outros (Org.) Direitos humanos e violência: desafios da ciência e da prática. Fortaleza: Fundação Konrad Adenauer, 2004, p.24.
} 
Assim, o inciso $\mathrm{X}$ do art. $7^{\circ}$ garante "proteção do salário na forma da lei, constituindo crime sua retenção dolosa". Entretanto, até o presente não foi promulgada qualquer lei definindo como crime a retenção dolosa do salário. Em razão disso, o Superior Tribunal de Justiça tem entendimento de que se não existe tipo penal, não há sanção a aplicar:

Ementa: HABEAS CORPUS. IMPETRAÇÃO SUBSTITUTIVA DE RECURSO ORDINÁRIO. IMPROPRIEDADE DA VIA ELEITA. APROPRIAÇÃO INDÉBITA. RETENÇÃO DE SALÁRIOS PELO EMPREGADOR. ATIPICIDADE RECONHECIDA. TRANCAMENTO DA AÇÃO PENAL ACOLHIDO. NÃO CONHECIMENTO DA IMPETRAÇÃO MAS CONCESSÃO DA ORDEM DE OFÍCIO. 1. É imperiosa a necessidade de racionalização do emprego do habeas corpus, em prestígio ao âmbito de cognição da garantia constitucional, e, em louvor à lógica do sistema recursal. In casu, foi impetrada indevidamente a ordem como substitutiva de recurso ordinário. 2. A retenção dolosa de salário, conquanto tenha sido prevista no art. $7^{\circ}, \mathrm{X}$ da Constituição Federal como crime, ainda ressente-se da necessária lei, criando o tipo penal respectivo. 3. Também não há como subsumir a conduta à apropriação indébita (art. 168 do Código Penal), porque o numerário ao qual o empregado tem direito, até que lhe seja entregue, em espécie ou por depósito, é de propriedade da empresa (empregador), não havendo se falar, então, em inversão da posse, necessária para a tipicidade do crime. 4. 0 administrador da empresa, ao assim agir, não pratica fato típico previsto no art. 168 do Código Penal. Talvez por isso tenha o legislador constituinte feito a previsão mencionada, mas ainda sem eficácia, ante a omissão legislativa. 5. Writ não conhecido, mas concedida a ordem, ex officio, para trancar a ação penal por atipicidade, ficando prejudicada a inépcia da denúncia e a alegação de que a paciente não seria administradora da pessoa jurídica. (STJ Habeas Corpus HC 177508 PB 2010/0118366-6, 6a Turma, Relatora Ministra MARIA THEREZA DE ASSIS MOURA DJ 26/08/2013) ${ }^{38}$ (grifos nossos)

O mesmo pode se dizer em relação aos direitos garantidos nos seguintes incisos do artigo $7^{\circ}$ da Constituição de 1988: garantia de "proteção do mercado de trabalho da mulher, mediante incentivos específicos, nos termos da lei" (inciso XX), adicional de remuneração para as atividades penosas (inciso XXIII ), "proteção em face de automação, na forma da lei" (inciso XXVII).

Para Jorge Miranda

\footnotetext{
${ }^{38}$ BRASIL. Superior Tribunal de Justiça. Habeas Corpus HC 177508 PB 2010/0118366-6, 6a Turma, Relatora Ministra MARIA THEREZA DE ASSIS MOURA DJ 26/08/2013. Disponível em: < https://stj.jusbrasil.com.br/ jurisprudencia/24135975/habeas-corpus-hc-177508-pb-2010-0118366-6-stj> Acesso em: 05 fev. 2017.
} 
Os direitos sociais abrangem tanto a educação, a saúde, o trabalho, o lazer, a segurança, a previdência social, a proteção à maternidade e à infância e a assistência aos desempregados como os direitos dos trabalhadores atinentes à segurança do empregado, ao salário, à associação sindical, à greve e à participação (arts. $6^{\circ}$ ao $11^{\circ}$ ). No que é, por certo, a mais grave deficiência do texto constitucional, só muito depois surge a 'ordem social' (arts. $193^{\circ}$ a $232^{\circ}$ ), evidentemente indissociável dos direitos sociais, mesmo quando se traduz em garantias institucionais e incumbências do Estado. Dominam aqui as normas programáticas, muitas delas de difícil cumprimento até a longo prazo, pelo menos da mesma maneira num país tão diversificado como o Brasil (e cuja estrutura federativa deveria recomendar maior plasticidade). ${ }^{39}$

Interessante a observação crítica de John D. French, historiador americano, que toca no problema da eficácia das normas contidas na Consolidação das Leis do Trabalho e na proliferação de normas no ordenamento jurídico brasileiro:

Para um historiador do trabalho acostumado com os Estados Unidos, uma primeira leitura da CLT decididamente produz um reação curiosa. Fica-se imediatamente atônito diante da extraordinária liberalidade com a qual a CLT estabelece direitos e garantias para os trabalhadores urbanos e suas organizações. Se o mundo do trabalho de fato funcionasse de acordo com a CLT, o Brasil seria o melhor lugar do mundo para se trabalhar. E se metade da CLT fosse mesmo cumprida, o Brasil ainda seria um dos lugares mais decentes e razoavelmente humanos para aqueles que trabalham em todo o mundo. ${ }^{40}$

A primeira grande mudança no texto de 1988 foi a posição reservada para os direitos trabalhistas. Nas ordens constitucionais anteriores, a matéria era tratada no capítulo intitulado "Da ordem econômica e social", que ficava no final do texto constitucional.

Daniel Sarmento sublinha que a forma de organização do texto da Constituição de 1988 é reveladora de algumas prioridades:

Se as constituições brasileiras anteriores iniciavam pela estrutura do Estado, e só depois passavam aos direitos fundamentais, a Constituição de 88 faz o contrário: consagra inicialmente os direitos e garantias fundamentais - no segundo título, logo depois daquele dedicado aos princípios fundamentais - só voltando-se depois disso à disciplina da organização estatal. Esta inversão topológica não foi

${ }_{39}$ MIRANDA, Jorge, op.cit., 1997, t. I, p.232.

${ }^{40}$ FRENCH, John D. Afogados em leis: A CLT e a cultura política dos trabalhadores brasileiros. São Paulo: Perseu Abramo, 2001, p.14-15. 
gratuita. Adotada em diversas constituições europeias do pós-guerra, após o exemplo da Lei Fundamental alemã de 1949, ela indica o reconhecimento da prioridade dos direitos fundamentais nas sociedades democráticas. ${ }^{41}$

Os direitos e garantias fundamentais compõem o título II da Constituição da República brasileira de 1988, subsequente apenas ao título que traça os princípios fundamentais do próprio Estado. Esse título divide-se em cinco capítulos, dos quais apenas o último, a tratar dos partidos políticos, não se refere diretamente ao homem, mas a um dos caminhos a ser por ele utilizado para o exercício de sua cidadania.

Hoje, a visualização de onde estejam os direitos dos trabalhadores na "geografia" constitucional é bastante clara: o Título II da Constituição de 1988 trata "Dos Direitos e Garantias Fundamentais". Dentro deste título está o capítulo II, denominado "Dos Direitos Sociais".

O interesse público e social na proteção dos direitos trabalhistas fica claro quando se constata que os direitos trabalhistas estão inseridos no Capítulo II do Título II - Dos Direitos e Garantias Fundamentais, da Constituição Federal brasileira. Os direitos trabalhistas se manifestam como de ordem pública, igualmente, a partir do caput do art. $7^{\circ}$ da CF, que estabelece que os direitos laborais atendem ao princípio da melhoria da condição social. ${ }^{42}$

Quis o constituinte demonstrar que os direitos trabalhistas têm grande importância, razão pela qual, diferentemente do que ocorria nas outras ordens constitucionais, foram colocados no início da nova Carta, em local de destaque.

Percebemos assim que o art. $7^{\circ}$ da Constituição de 1988, principal dispositivo a tratar de normas relativas a direito do trabalho, é direito social e, portanto, direito fundamental. Para Kátia Magalhães Arruda

É inegável a evolução trazida do ponto de vista de enquadramento dos direitos trabalhistas no elenco de direitos fundamentais, no entanto, a reflexão sobre o aspecto de 'leis inovadoras' mostra que a Constituição limitou-se a constitucionalizar ou ampliar direitos já existentes nas diversas leis esparsas e na CLT - Consolidação das Leis do Trabalho e reconhecer direitos largamente utilizados na realidade laboral cotidiana, confirmando a veracidade do conhecido princípio trabalhista da primazia da realidade. ${ }^{43}$

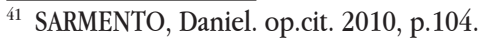

${ }^{42}$ CASTELO, Jorge Pinheiro. O direito material e processual do trabalho e a pós-modernidade: a CLT, o CDC e as repercussões do Novo Código Civil. São Paulo: LTr, 2003, p.243.

43 ARRUDA, Kátia Magalhães. Direito Constitucional do Trabalho: sua eficácia e o impacto do modelo neo-liberal. São Paulo: LTr, 1998, p.34-35. 
Notamos também, por meio do estudo do lugar escolhido pelo constituinte de 1988 para tratar dos direitos sociais, que a disposição do $\S 1^{\circ}$ do $\operatorname{art} .5^{\circ}$ da Constituição ${ }^{44}$ abrange todo o título atinente aos direitos e garantias fundamentais. Empós isso, basta lembrar que o trabalho está elencado como direito social no "caput" do art. $6^{\circ}$ da Carta Magna, razão porque os direitos e garantias a ele atinentes também possuem aplicação imediata.

Importante ressaltar que a doutrina brasileira é pacífica no sentido de ratificar que, por disposição constitucional expressa ( $\$ 1^{\circ}$ do art. $5^{\circ}$ da Constituição), as normas definidoras dos direitos e garantias fundamentais têm aplicação imediata.

As características do sistema de direito do trabalho brasileiro podem ser extraídas da Constituição Federal de 1988, da Consolidação das Leis do Trabalho e das fontes do direito do trabalho. A Constituição Federal de 1988 assenta desde sua epígrafe que visa assegurar o exercício dos direitos sociais (dentre os quais estão os direitos trabalhistas). Um dos fundamentos da República Federativa do Brasil, inscrito no primeiro artigo da Constituição de 1988, é o valor social do trabalho.

O capítulo II da Constituição de 1988 é intitulado "Dos direitos sociais" e contém no artigo $7^{\circ}$ um rol apenas exemplificativo de 34 incisos tratando de direitos e garantias dos trabalhadores urbanos e rurais. A parte final do "caput" do artigo $7^{\circ}$ da Constituição de 1988 é explícita no sentido de que os direitos ali inscritos não são taxativos, mas sim meramente exemplificativos, pois ao contrário de vedar a existência de outros direitos, ressalta que pode haver outros que visem a melhoria da condição social dos trabalhadores.

Portanto, o sistema de direito do trabalho no Brasil tem por escopo a melhoria da condição social dos trabalhadores conforme dita a parte final do "caput" do artigo $7^{\circ}$ da Constituição de 1988. Essa característica do sistema se coaduna com a evolução histórica do próprio direito do trabalho no Brasil e no mundo. Partiuse de um período em que não havia qualquer preocupação com o regramento das situações envolvendo o labor humano para um estágio em que a Revolução Industrial ensejou lutas sociais pelo desenvolvimento de normas que regulassem o labor humano e limitassem sua exploração.

O sistema de direito do trabalho brasileiro também é calcado em princípios próprios ou peculiares, que foram enumerados por Américo Plá Rodriguez na clássica obra "Princípios do Direito do Trabalho". Os princípios tem função

\footnotetext{
$\overline{{ }^{4} 4}$ Art. $5^{\circ}, \S 1^{\circ} \mathrm{da} \mathrm{CF} / 88$ : "As normas definidoras dos direitos e garantias fundamentais têm aplicação imediata."
} 
informadora, normativa e interpretativa. A função informadora dos princípios do direito do trabalho é aquela de inspirar o legislador na criação das normas que comporão o ordenamento jurídico laboral. A função normativa é aquela pela qual os princípios do direito do trabalho atuarão como meio supletivo de colmatar as lacunas existentes no ordenamento jurídico laboral (artigo $8^{\circ}$ da CLT). A função interpretativa é aquela segundo a qual os princípios do direito do trabalho operarão como critério orientador para o intérprete da norma jurídica.

Princípios do direito do trabalho são "as regras dogmáticas básicas que servem de alicerce para a sistematização do ordenamento jurídico trabalhista.” ${ }^{45}$

São princípios específicos ou peculiares do direito do trabalho, segundo Américo Plá Rodriguez ${ }^{46}$ : o princípio da proteção que se subdivide em princípio do "in dubio pro operario", princípio da aplicação da norma mais favorável ao trabalhador e princípio da aplicação da condição mais benéfica ao trabalhador; princípio da indisponibilidade ou irrenunciabilidade de direitos; princípio da continuidade da relação de emprego; princípio da primazia da realidade; princípio da razoabilidade e princípio da boa-fé. Os doutrinadores citam outros princípios além daqueles indicados por Américo Plá Rodriguez, mas para os fins deste estudo nos limitaremos à doutrina clássica.

A jurisprudência trabalhista utiliza com frequência os princípios de direito do trabalho para solução de conflitos trabalhistas.

Da análise do texto constitucional vigente, especificamente o artigo $7^{\circ} \mathrm{da}$ Constituição de 1988, e dos princípios do direito do trabalho podemos afirmar que o sistema de direito do trabalho brasileiro é um sistema aberto no sentido de que permite o ingresso no ordenamento jurídico de normas que visem à melhoria da condição social do trabalhador (parte final do "caput" do artigo $7^{\circ} \mathrm{da}$ Constituição de 1988).

A interpretação do sistema de direito do trabalho brasileiro deve orientarse pelos princípios do direito do trabalho em razão de suas funções e de expressa disposição legal (artigo $8^{\circ} \mathrm{da}$ CLT).

Assim, o sistema de direito do trabalho brasileiro é um sistema aberto que visa a melhoria das condições sociais dos trabalhadores e a proteção de seus direitos.

\footnotetext{
$\overline{45}$ PINTO, José Augusto Rodrigues e PAMPLONA FILHO, Rodolfo. Repertório de conceitos trabalhistas. São Paulo, LTr, 2000,p.419.

${ }^{46}$ RODRIGUEZ, Américo Plá. Princípios de Direito do Trabalho. 3. ed. São Paulo, LTr, 2000.
} 


\section{ANÁLISE DE ALGUNS PONTOS DA REFORMA TRABALHISTA (LEI 13467 DE 13/07/2017)}

A lei 13467 de 13/07/2017 entrará em vigor no prazo de 120 dias de sua publicação (artigo $6^{\circ}$ ) e trata do que se convencionou denominar de "reforma trabalhista". Referida norma jurídica traz em seu bojo que tem por "fim de adequar a legislação às novas relações de trabalho."

Assim, em tese, a lei 13467/2017 teria por escopo adequar o sistema de direito do trabalho brasileiro de forma a manter sua coerência com os fatos sociais ou "novas relações de trabalho".

Entretanto, da leitura da lei 13467/2017 percebe-se que ela vai muito além de meramente tentar adequar a legislação às novas relações de trabalho, visto que alterou não só dispositivos de direito material, mas também de direito processual e de hermenêutica. Trataremos de alguns pontos trazidos pela reforma trabalhista como forma de analisar se ela se adequa ou não à noção de sistema jurídico.

$O$ artigo $8^{\circ}$ da CLT, na sua redação original, diz

Art. $8^{\circ}$ - As autoridades administrativas e a Justiça do Trabalho, na falta de disposições legais ou contratuais, decidirão, conforme o caso, pela jurisprudência, por analogia, por eqüidade e outros princípios e normas gerais de direito, principalmente do direito do trabalho, e, ainda, de acordo com os usos e costumes, o direito comparado, mas sempre de maneira que nenhum interesse de classe ou particular prevaleça sobre o interesse público.

Parágrafo único - O direito comum será fonte subsidiária do direito do trabalho, naquilo em que não for incompatível com os princípios fundamentais deste.

A primeira alteração significativa efetuada pela lei 13467/2017 foi exatamente no parágrafo único do artigo $8^{\circ} \mathrm{da}$ CLT, que passou a ser parágrafo primeiro e houve inserção de mais dois parágrafos. Eis a nova redação dos parágrafos do artigo $8^{\circ} \mathrm{da}$ CLT:

$\S 1^{\circ}$ O direito comum será fonte subsidiária do direito do trabalho. $\S 2^{\circ}$ Súmulas e outros enunciados de jurisprudência editados pelo Tribunal Superior do Trabalho e pelos Tribunais Regionais do Trabalho não poderão restringir direitos legalmente previstos nem criar obrigações que não estejam previstas em lei.

$\S 3^{\circ}$ No exame de convenção coletiva ou acordo coletivo de trabalho, a Justiça do Trabalho analisará exclusivamente a conformidade dos elementos essenciais do negócio jurídico, respeitado o disposto no art. 104 da Lei no 10.406, de 10 de janeiro de 2002 (Código Ci- 
vil), e balizará sua atuação pelo princípio da intervenção mínima na autonomia da vontade coletiva.

Note-se que o alcance do antigo parágrafo único do artigo $8^{\circ}$ da CLT, que dizia que o direito comum será fonte subsidiária do direito do trabalho naquilo em que não for incompatível com os princípios fundamentais deste, foi diminuído. Com a vigência da lei 13467/2017 a redação será apenas " o direito comum será fonte subsidiária do direito do trabalho".

Essa alteração demonstra que a noção de sistema não foi respeitada, visto que os princípios do Direito do Trabalho têm funções específicas (informadora, normativa e interpretativa) e não é aconselhável a existência de um sistema em que haja incompatibilidades entre suas normas e seus princípios informadores.

Nesse ponto considera-se que a alteração realizada por meio da lei 13467/2017 não melhorou nem dinamizou o sistema de direito do trabalho brasileiro. Ao contrário. Como o "caput" do artigo $8^{\circ}$ da CLT permanece inalterado, os princípios de direito do trabalho continuam a exercer as funções informadora, normativa e interpretativa de maneira relevante por expressa disposição do artigo $8^{\circ}$ da própria CLT.

Interessante também neste aspecto lembrar que o artigo 769 da CLT, que dispõe que "nos casos omissos, o direito processual comum será fonte subsidiária do direito processual do trabalho, exceto naquilo em que não for incompatível com as normas deste título", não foi revogado nem alterado pela lei 13467/2017.

Aparentemente existe incongruência da lei 13467/2017 neste tocante, visto que tentou extirpar a incidência dos princípios de direito material do trabalho ao alterar o parágrafo único do artigo $8^{\circ}$ da CLT em sua redação original, mas nada tratou sobre as normas de direito processual.

Ao tratar o tema, Maurício Godinho Delgado e Gabriela Neves Delgado afirmam:

A nova lei produziu, ademais, a inserção de dois novos dispositivos, os $\S \S 2^{\circ}$ e $3^{\circ}$ do art. $8^{\circ}$, que procuram instituir limitações ao processo de interpretação jurídica no âmbito da Justiça do Trabalho. (...) As fontes subsidiárias do Direito do Trabalho - aquelas que irão permitir a integração jurídica, sendo utilizadas, se necessário, para reger determinado caso concreto quando a CLT mostrar-se efetivamente omissa - estão lançadas, como percebido, no caput do art. $8^{\circ}$ da Consolidação das Leis do Trabalho. Não tendo esse preceito sofrido qualquer alteração por parte da Lei n. 13.467/2017, pode-se afirmar, 
com tranquilidade, que o novo diploma legal não trouxe qualquer mudança importante no que tange ao tema da integração jurídica. Mesmo com relação à mudança redacional estabelecida para o $\S 1^{\circ}$ do art. $8^{\circ}$ (antigo parágrafo único), ela não é substantiva, na verdade. Ora, suprimiu-se, conforme se nota, a referência à expressão "naquilo em não for incompatível com os princípios fundamentais deste" (eis o antigo texto legal do parágrafo único: "O direito comum será fonte subsidiária do direito do trabalho, naquilo em que não for incompatível com os princípios fundamentais deste"). Porém, não pode haver dúvida de que a regra subsidiária somente pode ser importada para o suprimento das lacunas nas fontes principais do campo jurídico analisado se realmente for compatível com ele, isto é, compatível com a sua estrutura normativa, com a sua lógica jurídica e com os seus princípios jurídicos essenciais. Em um segundo plano, os novos $\S \S 2^{\circ}$ e $3^{\circ}$ do art. $8^{\circ}$ da CLT - que foram inseridos pela Lei n. 13.467/2017 - buscam fixar restrições à atuação da Justiça do Trabalho, com limitações à interpretação jurídica realizada por esse segmento do Poder Judiciário Federal. ${ }^{47}$

Ademais, vislumbra-se que a técnica legislativa utilizada não foi das mais recomendadas, visto que em alguns trechos a lei 13467/2017 cuidou de estabelecer o que não caracterizaria determinado instituto jurídico no lugar de conceituá-lo. Ou seja: a lei tratou de definir as exceções à regra, e não a regra geral, o que é considerado boa técnica legislativa. Isso foi feito na modificação do artigo $4^{\circ}$ da CLT, que trata do tempo à disposição do empregador, para inserir o $\S^{\circ}$ do artigo $4^{\circ} \mathrm{da}$ CLT e dizer o que não caracteriza tempo de trabalho. O mesmo ocorreu na alteração do artigo $2^{\circ} \mathrm{da}$ CLT para inserir o $3^{\circ}$ e dizer o que não caracteriza grupo econômico além do $\S 2^{\circ}$ do artigo 58 da CLT que diz o que não configura tempo "in itinere".

Trata-se de uma lógica invertida: em vez de enunciar o que seria o instituto jurídico sob exame, declara-se casuisticamente hipóteses que não configuram o instituto.

Um exemplo de boa utilização da lei 13467/2017 ao conceito de sistema foi a alteração perpetrada no artigo $11 \mathrm{da}$ CLT, que serviu para modificar o texto da CLT e adequá-lo ao disposto no inciso XXIX do artigo $7^{\circ}$ da Constituição de 1988 que diz respeito à prescrição dos créditos trabalhistas. A alteração realizada corrigiu uma distorção de quase 30 anos, pois desde sua vigência a Constituição de 1988 alterou o parâmetro da contagem do prazo prescricional dos créditos

47 DELGADO, Maurício Godinho e DELGADO, Gabriela Neves. A reforma trabalhista no Brasil: com os comentários à Lei 13467/2017. São Paulo: LTr, 2017; p.104 e 106. 
trabalhistas e a CLT continuava com redação que não havia sido recepcionada. Com isso o problema terminou e privilegiou-se a ideia de um sistema uno e coerente logicamente. Os parágrafos $2^{\circ}$ e $3^{\circ}$ do artigo 11 da CLT são reprodução de entendimentos jurisprudenciais sumulados pelo Tribunal Superior do Trabalho que agora se transformam em texto de lei.

A introdução do artigo 11-A da CLT por meio da lei 13467/2017, que trata da prescrição intercorrente, deve levar ao cancelamento da súmula de jurisprudência 114 do Tribunal Superior do Trabalho que dispõe expressamente que não se aplica à prescrição intercorrente na Justiça do Trabalho. Note-se aqui que a noção de sistema funciona como de uma estrutura em que seus elementos mantêm relações entre si. O texto do novel artigo 11-A da CLT é completamente incompatível com o conteúdo da súmula 114 do TST. Sendo o artigo 11-A da CLT texto de lei compatível com a Constituição, é hierarquicamente superior ao conteúdo da súmula 114 do TST, razão pela qual a mesma deverá ser cancelada como forma de manter a coerência e unidade do sistema de direito do trabalho brasileiro.

No mesmo sentido o entendimento doutrinário abaixo transcrito:

O caput do art. 11 apenas veio atualizar o que já tínhamos quanto à prescrição na Justiça do Trabalho, sendo que, o trabalhador possui 2 anos para ingressar na Justiça do Trabalho e que poderá pleitear os últimos 5 anos. Também foi mantida a imprescritibilidade das reclamatórias para fins de anotações na CTPS, nos moldes do $§ 10 .{ }^{48}$

Outro bom exemplo de adequação da norma ao fato social, que revela preocupação do legislador com a efetividade da norma jurídica e sua aplicabilidade foi a alteração propugnada no artigo 47 da CLT pela lei 13467/2017 com a finalidade de fixar parâmetros pecuniários atuais condizentes para multa fixada naquele artigo.

A alteração no artigo 58-A da CLT, que trata do trabalho a tempo parcial, foi para aumentar a jornada máxima de 25 horas de trabalho semanal para 30 horas de trabalho semanal e explicitar o regime de férias, horas extras e compensação de horários desses empregados.

O artigo 59 com redação dada pela lei 13467/2017 veio explicitar que a jornada de trabalho pode ser aumentada por meio de acordo individual, convenção coletiva ou acordo coletivo - entendimento já pacificado pela doutrina e jurisprudência.

${ }^{48}$ CAVALCANTE, Rodrigo Arantes e VAL, Renata do. Reforma trabalhista: comentada artigo por artigo. São Paulo: LTr, 2017, p.30. 
O $\xi^{\circ}$ do artigo 71 da CLT alterou a natureza jurídica da remuneração do intervalo para repouso e alimentação que tenha sido suprimido do trabalhador, que passou a ser indenizatória quando o entendimento doutrinário e jurisprudencial até então dominantes era de que a natureza jurídica dessa parcela era salarial.

Foi inserido um capítulo na CLT relativo ao teletrabalho - fato social advindo das novas tecnologias utilizadas no mundo do trabalho e que demonstra nesse ponto que a lei 13467/2017 buscou adequar a legislação à nova realidade.

$O$ parágrafo $1^{\circ}$ do artigo 134 da CLT foi alterado para permitir que as férias do empregado possam ser fracionadas em até três períodos desde que o empregado com isso concorde e que um dos períodos não seja inferior a 14 dias.

A reforma trabalhista criou o título II-A na CLT, que vai dos artigos 223-A até 233-G que tratam da reparação dos danos extrapatrimoniais. O tema já é amplamente conhecido e debatido na doutrina e jurisprudência, mas o §1 $1^{\circ}$ do artigo 223-G da CLT traz um sistema de tarifação do valor da indenização do dano extrapatrimonial, o que não parece razoável por usar como base de cálculo o valor do último salário contratual do ofendido se este for pessoa natural ou do ofensor caso o ofendido seja pessoa jurídica.

Para Noemia Porto,

Evidentemente, observada a supremacia da Constituição, é inviável que a lei infraconstitucional impeça que a análise de questões que envolvam danos extrapatrimoniais tenha como referência a estrutura normativa dedicada à prevalência dos direitos fundamentais. Portanto, a regulação especial voltada às relações de trabalho deve ser interpretada, necessariamente, sob a melhor luz da Constituição, o que concretamente significa o compromisso reiterado com a realização de direitos fundamentais, percebendo-se no direito à reparação uma forma de garantia a esses direitos. ${ }^{49}$

Acreditamos que as mudanças inseridas pelo artigo 394-A da CLT que tratam do trabalho da mulher gestante em ambiente insalubre sejam incompatíveis com as normas de medicina e segurança do trabalho postas na CLT e nas Normas Regulamentadoras do Ministério do Trabalho, pelo que pensamos que a mesma não se adequa ao sistema de direito do trabalho brasileiro.

O artigo 442-B da CLT diz: "Art. 442-B. A contratação do autônomo,

49 PORTO, Noemia. Dano extrapatrimonial e reforma trabalhista: análise sobre o alcance dos direitos fundamentais. In: FELICIANO, Guilherme Guimarães e outros (organizadores). Reforma trabalhista: visão, compreensão e crítica. São Paulo: LTr, 2017,p.139. 
cumpridas por este todas as formalidades legais, com ou sem exclusividade, de forma contínua ou não, afasta a qualidade de empregado prevista no art. $3^{\circ}$ desta Consolidação." Referida disposição legal não se adequa ao sistema de direito do trabalho brasileiro porque macula o princípio peculiar do direito do trabalho da primazia da realidade, segundo o qual a realidade fática (os fatos) se sobrepõem às aparências ou aos documentos.

Conclui Saulo Tarcísio de Carvalho Fontes que

A pretensão indisfarçável da inovação legal, com ou sem a exclusividade, é buscar afastar a aplicação do princípio da primazia da realidade, criando óbice à eventual reconhecimento de relação de emprego em contratos que sejam estabelecidos formalmente como de natureza diversa. ${ }^{50}$

Portanto, se a contratação do autônomo estiver descaracterizada formarse-á o vínculo de emprego com o tomador de serviços desde que presentes os requisitos do artigo $3^{\circ}$ da CLT. O sistema de direito do trabalho brasileiro prestigia a verdade, aquilo que realmente ocorreu no mundo fático, razão pela qual a lei não tem o condão de transformar a realidade.

\section{CONSIDERAÇÕES FINAIS}

O sistema é uma criação do jurista que busca organizar as normas jurídicas para melhor aplicação do direito. Portanto, o sistema é como uma grande estrutura, cujas vigas mestras são postas de maneira sólida e não devem ser modificadas sob pena de destruir ou abalar a estrutura. Os elementos que estão dentro da estrutura denominada sistema devem ser harmônicos e compatíveis entre si.

A Constituição da República Federativa do Brasil, promulgada em 1988, foi revolucionária no que diz respeito à inserção de uma série de direitos voltados aos trabalhadores, conferindo-lhes "status" de direitos fundamentais e aplicabilidade imediata.

O sistema de direito do trabalho brasileiro tem como fontes a Constituição de 1988, a Consolidação das Leis do Trabalho e as fontes do direito do trabalho

\footnotetext{
${ }^{50}$ FONTES, Saulo Tarcísio de Carvalho. A natureza das coisas: o "trabalhador autônomo exclusivo" e a Constituição. In: FELICIANO, Guilherme Guimarães (Org.). Reforma trabalhista: visão, compreensão e crítica. São Paulo: LTr, 2017, p.78.
} 
(artigo $8^{\circ}$ da CLT). Os princípios peculiares do direito do trabalho tem função normativa, interpretativa e informadora. As características do sistema de direito do trabalho brasileiro são, dentre outras, o escopo de melhorar a condição social dos trabalhadores (parte final do "caput" do artigo $7^{\circ}$ da Constituição de 1988) e aquelas firmadas pelos princípios peculiares do direito do trabalho.

A lei 13467/2017, conhecida por reforma trabalhista, propõe na sua ementa adequar a legislação às novas relações de trabalho, mas faz muito mais que isso, pois também tratou de aspectos processuais e hermenêuticos.

Vislumbramos que alguns pontos da reforma trabalhista não se adequam à noção de sistema que tem o direito do trabalho brasileiro, pois são contraditórias e incompatíveis com a principiologia peculiar do direito do trabalho, a exemplo do $\S 1^{\circ}$ do artigo $8^{\circ}$ da CLT, e dos ditames da Constituição Federal de 1988 no sentido de que são direitos dos trabalhadores todos aqueles elencados no artigo $7^{\circ}$, além de outros que visem à melhoria de sua condição social.

A moderna hermenêutica privilegia a concretização dos comandos constitucionais, razão pela qual podemos afirmar que os trechos da reforma trabalhista (lei 13467/2017) que tratam de direito material não se coadunam com a noção de sistema jurídico, pois não guardam coerência nem unidade com a vontade constitucional de melhoria da condição social dos trabalhadores nem com os princípios peculiares do direito do trabalho.

Importante frisar que enquanto no direito material do trabalho a legislação é protetiva dos direitos e garantias do sujeito trabalhador por razões históricas, filosóficas e econômicas, essa distinção não ocorre no direito processual do trabalho, em que deve haver paridade de armas entre os sujeitos do processo. Desta forma, o princípio do "in dubio pro operario" somente deve ser utilizado quando houver dúvida sobre a aplicação da norma de direito material.

Podemos concluir que a lei 13467/2017 se adequa de forma apenas parcial ao sistema de direito do trabalho brasileiro, visto que nos itens em que há incompatibilidade com princípios peculiares do direito do trabalho não se pode falar em sua integração ao sistema jurídico trabalhista. De um modo geral a reforma trabalhista foi casuísta, pois focou-se em extirpar temas ou matérias controvertidas na jurisprudência dos tribunais, a exemplo do tempo "in itinere", do dano moral por utilização de logomarcas em uniforme de trabalho, e não em criar normas que se adequassem ao sistema de direito do trabalho brasileiro. 


\section{REFERÊNCIAS}

ARRUDA, Kátia Magalhães. Direito Constitucional do Trabalho:sua eficácia e o impacto do modelo neo-liberal. São Paulo: LTr, 1998.

BALEEIRO, Aliomar. Constituições Brasileiras:1891. Brasília: Senado Federal e Ministério da Ciência e Tecnologia, Centro de Estudos Estratégicos, 1999.

BALEEIRO, Aliomar; LIMA SOBRINHO, Barbosa. Constituições Brasileiras: 1946. Brasília: Senado Federal e Ministério da Ciência e Tecnologia, Centro de Estudos Estratégicos, 1999.

BRASIL. Consolidação das Leis do Trabalho. 46. ed. São Paulo: LTr, 2016.

BRASIL. Superior Tribunal de Justiça. Habeas Corpus HC 177508 PB 2010/01183666 , $6^{\text {a }}$ Turma, Relatora Ministra MARIA THEREZA DE ASSIS MOURA DJ 26/08/2013. Disponível em: <https://stj.jusbrasil.com.br/jurisprudencia/24135975/habeascorpus-hc-177508-pb-2010-0118366-6-stj> . Acesso em: 05 fev. 2017.

BETIOLI, Antonio Bento. Introdução ao direito: lições de propedêutica jurídica tridimensional. 12.ed. São Paulo: Saraiva, 2013.

BOBBIO, Norberto. A era dos direitos. 8. ed. Rio de Janeiro: Campus, 1992.

CANARIS, Claus-Wilhelm. Pensamento sistemático e conceito de sistema na ciência do direito. 5.ed. Lisboa: Fundação Calouste Gulbenkian, 2012.

CASTELO, Jorge Pinheiro. 0 direito material e processual do trabalho e a pósmodernidade: a CLT, o CDC e as repercussões do Novo Código Civil. São Paulo: LTr, 2003.

CAVALCANTE, Rodrigo Arantes e VAL, Renata do. Reforma trabalhista: comentada artigo por artigo. São Paulo: LTr, 2017

CUNHA, Antônio Geraldo da. Dicionário Etimológico Nova Fronteira da Língua Portuguesa. 2. ed., Rio de Janeiro, Nova Fronteira, 1986.

DELGADO, Maurício Godinho; DELGADO, Gabriela Neves. A reforma trabalhista 
no Brasil: com os comentários à Lei 13467/2017. São Paulo: LTr, 2017.

DINIZ, Maria Helena. Compêndio de introdução à ciência do direito. 18. ed. São Paulo: Saraiva, 2006.

DINIZ, Maria Helena. Sistematização: problema central da ciência jurídica. Revista de Direito Brasileira, São Paulo, v. 13, n. 6, p. 88-94, jan./abr. 2016.

FERRARI, Irany et al. História do trabalho, do direito do trabalho e da justiça do trabalho. São Paulo: LTr, 1998.

FONTES, Saulo Tarcísio de Carvalho. A natureza das coisas: o "trabalhador autônomo exclusivo" e a Constituição. In: FELICIANO, Guilherme Guimarães (Org.). Reforma trabalhista: visão, compreensão e crítica. São Paulo: LTr, 2017.

FRENCH, John D. Afogados em leis: A CLT e a cultura política dos trabalhadores brasileiros. São Paulo: Perseu Abramo, 2001.

GAMA, Tacio Lacerda. Sistema jurídico: perspectiva dialógica. In: CAMPILONGO, Celso Fernandes; GONZAGA, Alvaro de Azevedo; FREIRE, André Luiz (Coord.). Enciclopédia jurídica da PUC-SP. Tomo: Teoria Geral e Filosofia do Direito. São Paulo: Pontifícia Universidade Católica de São Paulo, 2017. Disponível em: < https:// enciclopediajuridica.pucsp.br/verbete/100/edicao-1/sistema-juridico---perspectivadialogica > . Acesso em: 03 maio 2017.

LARENZ, Karl. Metodologia da ciência do direito. 3. ed. Lisboa: Fundação Calouste Gulbenkian, 1997.

LOBATO, Anderson Orestes Cavalcante. Os direitos humanos na Constituição brasileira: os desafios da efetividade. In: MALUSCHKE, Gunther (Org.). Direitos humanos e violência : desafios da ciência e da prática. Fortaleza: Fundação Konrad Adenauer, 2004.

MEIRELES, Edilton. Constituição do trabalho: O trabalho nas Constituições da Alemanha, Brasil, Espanha, França, Itália e Portugal. 2. ed. São Paulo: LTr, 2014.

MIRANDA, Jorge. Manual de Direito Constitucional. 6. ed. Coimbra: Coimbra, 1997 , t. I. 
NAGAO, Paulo Issamu. O papel do juiz na efetividade do processo civil contemporâneo. São Paulo: Malheiros, 2016.

NASCIMENTO, Amauri Mascaro. Curso de Direito do Trabalho. 19. ed. São Paulo: Saraiva, 2004.

NOGUEIRA, Octaciano. Constituições Brasileiras:1824. Brasília: Senado Federal e Ministério da Ciência e Tecnologia, Centro de Estudos Estratégicos, 1999.

PINTO, José Augusto Rodrigues; PAMPLONA FILHO, Rodolfo. Repertório de conceitos trabalhistas. São Paulo, LTr, 2000.

POLETTI, Ronaldo. Constituições Brasileiras: 1934. Brasília: Senado Federal Ministério da Ciência e Tecnologia, 1999.

PORTO, Noemia. Dano extrapatrimonial e reforma trabalhista: análise sobre o alcance dos direitos fundamentais. In: FELICIANO, Guilherme Guimarães (Org.). Reforma trabalhista: visão, compreensão e crítica. São Paulo: LTr, 2017.

PORTO, Walter Costa. Constituições Brasileiras: 1937. Brasília: Senado Federal e Ministério da Ciência e Tecnologia, Centro de Estudos Estratégicos, 1999.

RODRIGUEZ, Américo Plá. Princípios de Direito do Trabalho. 3. ed., São Paulo, LTr, 2000.

ROMITA, Arion Sayão. Os direitos sociais na Constituição e outros estudos. São Paulo: LTr, 1991.

SARLET, Ingo Wolfgang. A eficácia dos direitos fundamentais: uma teoria geral dos direitos fundamentais na perspectiva constitucional. 10. ed. Porto Alegre: Livraria do Advogado, 2010.

SARMENTO, Daniel. Por um constitucionalismo inclusivo : história constitucional brasileira, teoria da Constituição e direitos fundamentais. Rio de Janeiro: Lumen Juris, 2010.

STRECK, Lenio Luiz. Jurisdição constitucional e hermenêutica: uma nova crítica 
do direito. 2. ed. Rio de Janeiro: Forense, 2004.

SÜSSEKIND, Arnaldo. Direito Constitucional do Trabalho. 3. ed. Rio de Janeiro: Renovar, 2003.

VIEIRA, José Roberto. A noção de sistema no direito. Revista da Faculdade de Direito da UFPR. Curitiba, v. 33, p. 53-64, 2000. Disponível em: < http://revistas. ufpr.br/direito/article/download/1844/1540> Acesso em 20 nov. 2017.

Recebido em: 2017-10-02

Aceito em: 2018-03-21 